\title{
Effect of ice massage with integrated neuromuscular inhibition technique on pain and function in subjects with mechanical neck pain: randomized controlled trial
}

\author{
Heba Mohammed Moselhy Al-Najjar ${ }^{1 *}$ (D, Amal Hassan Mohammed² and Dalia Mohammed Mosaad²
}

\begin{abstract}
Background: Myofascial trigger point (MTrP) plays a major role in the genesis of mechanical neck pain, which may lead to chronic disorders. The purpose of the study is to investigate and compare the effect of ice massage plus integrated neuromuscular inhibition technique (INIT) versus INIT alone on active trigger points in the upper trapezius of persons having mechanical neck pain. Forty participants diagnosed as mechanical neck pain with upper trapezius active myofascial trigger points. They were randomized into two equal groups. Group A (experimental) received ice massage for 10 min plus INIT, while group B (control) received INIT alone. The treatment program continued for 2 weeks ( 3 sessions/week). The outcome measures are the pain intensity, pain pressure threshold, cervical lateral side bending and neck daily functions.

Results: The results showed that there were significant improvements in VAS at $p=.899$ and $F=.78$, PPT at $p=$ .288 and $F=.553$, cervical side bending at $p=.094$ and $F<0.00001$, and NDI at $p=.164$ and $F=0.00001$ in both groups, while there were no statistically significant differences between both groups as $p>0.05$.

Conclusion: Ice massage and INIT are effective methods in managing active trigger points in the upper trapezius of persons having mechanical neck pain without statistically significant difference.
\end{abstract}

Keywords: Ice massage, Integrated neuromuscular inhibition technique, Mechanical neck pain

\footnotetext{
*Correspondence: Dhebaelnagar79@gmail.com

${ }^{1}$ Cairo University, Giza, Egypt

Full list of author information is available at the end of the article
}

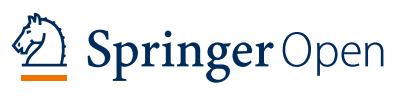

(c) The Author(s). 2020 Open Access This article is licensed under a Creative Commons Attribution 4.0 International License, which permits use, sharing, adaptation, distribution and reproduction in any medium or format, as long as you give appropriate credit to the original author(s) and the source, provide a link to the Creative Commons licence, and indicate if changes were made. The images or other third party material in this article are included in the article's Creative Commons licence, unless indicated otherwise in a credit line to the material. If material is not included in the article's Creative Commons licence and your intended use is not permitted by statutory regulation or exceeds the permitted use, you will need to obtain permission directly from the copyright holder. To view a copy of this licence, visit http://creativecommons.org/licenses/by/4.0/. 


\section{Background}

Mechanical neck pain is a prevalent condition in various populations. Neck pain occurrence is affected by several factors, involving environmental, psychological, and social aspects. The absence of diagnosis and proper management of the underlying pathology can result in chronic conditions, as well as very high medical and socioeconomic costs [1].

Neck pain represents the fourth major disorder responsible for a person's year lived with disability and ranked eleventh as disability adjusted life years of a person. The neck pain incidence ranges from 10.4 to $23.3 \%$ in 1-year time, while the range of prevalence was 0.4 to $86.8 \%$. It has a high prevalence among computer users, office workers, and females, especially females aged 35 to 49 years old [2, 3].

Myofascial trigger point (MTrP) might play an important role in the formation of mechanical neck pain and is known as a hyperirritable spot in skeletal muscle that is accompanied with a hypersensitive palpable nodule in a taut band. There are many causing factors such as mechanical, nutritional, metabolic, and psychological factors resulting in the genesis of trigger points. Tender spot in the taut band in skeletal muscles, palpable or visible local twitch response, jump sign, typical referred pain pattern, and limitation of range of motion are the important signs of MTrPs [4].

Cryotherapy causes a significant raise in pain threshold and decrease in nerve conduction velocity and vasodilatation following hunting response, increases nutrition, and enhances blood circulation to deep tissues and muscles [5]. In the past, clinicians have found that for treating MTrPs, most of the patients preferred heat application rather than cold; however, some patients preferred cold application to MTrPs, and some researchers prove that ice massage is ineffective in decreasing the indirect markers related to exercise-induced muscle damage [6]. So there is a debate in using cold application with MTrP. Very limited evidence has been found on the effect of cryotherapy in acute non-specific neck pain, and there are more needs for more sufficiently powered high-quality RCTs on the effects of cold and heat therapy on recovery from acute musculoskeletal injury $[7,8]$.

The present study hypothesized that there are no statistically significant differences between the effects of ice massage plus integrated neuromuscular inhibition technique (INIT) versus INIT alone on pain, cervical lateral side bending, and neck functional abilities during treatment of trigger points in the upper trapezius of persons having mechanical neck pain.

\section{Methods}

\section{Design}

This is a prospective, parallel-group, randomized clinical trial.

\section{Subjects}

Forty participants (female and male) were recruited from physical therapy outpatient clinic, El-sheikh Zaid Family Medicine Center, Ministry of Health and Population, according to the inclusion and exclusion criteria. Their age ranged from 18 to 35 years. Subjects were included if they were diagnosed as non-specific neck pain with upper trapezius active myofascial trigger points less than 3 months of duration and have these criteria: taut band on palpation, hypersensible tender spot in taut band, local twitch response, referred pain pattern, and body mass index from 18 to $25 \mathrm{~kg} / \mathrm{m}^{2}$. Subjects were excluded if they had trigger point injections within the past 6 months, history of neck or upper back surgery, trauma or fracture, history of a whiplash injury, skin diseases and lesions, any sensory disturbances, any vascular syndromes, neck and back deformities, cervical radiculopathy, and diagnosis of fibromyalgia syndrome, skin diseases, lesions or malignancy.

All participants agreed and signed a free consent form for ethical issue and received verbal and written explanation for the purpose of the study. Random allocations were determined by a computer-generated random number program. Allocation was concealed by placing the random allocations in opaque sealed envelopes. Group A received ice massage plus INIT for 2 weeks ( $n$ $=20)$, and group B received INIT for 2 weeks $(n=20)$. Figure 1 shows the study flaw chart of the study. All participants were treated in the physical therapy outpatient clinic, El-sheikh Zaid Family Medicine Center, Ministry of Health and Population.

The primary outcome is pain intensity.

The secondary outcomes are pain pressure threshold, cervical lateral side bending as it is the main action of upper fiber of the trapezius, and neck functional abilities.

\section{Instrumentation for assessment}

All patients were assessed before and after the treatment program. The assessment procedures include the following:

Pain intensity assessment VAS, which consists of a line, usually $10 \mathrm{~cm}$ long; the patient would be instructed to place a vertical mark on to represent his/her pain, with 0 indicating no pain and 10 indicating the worst pain [9].

Neck disability index (NDI, Arabic version) which has high validity and reliability. It consists of 10 multiple choice questions for neck pain, where the patient selects one sentence out of six that best describes their function; higher score indicates great loss of function.

The overall score could range from 0 (the highest functional level) to 50 (the lowest functional level). Disability score percentage were calculated as scores of 10-28\% which indicated mild disability, 30-48\% which indicated moderate disability, 50-68\% which indicated severe disability, and $\geq 72 \%$ which indicated complete disability 


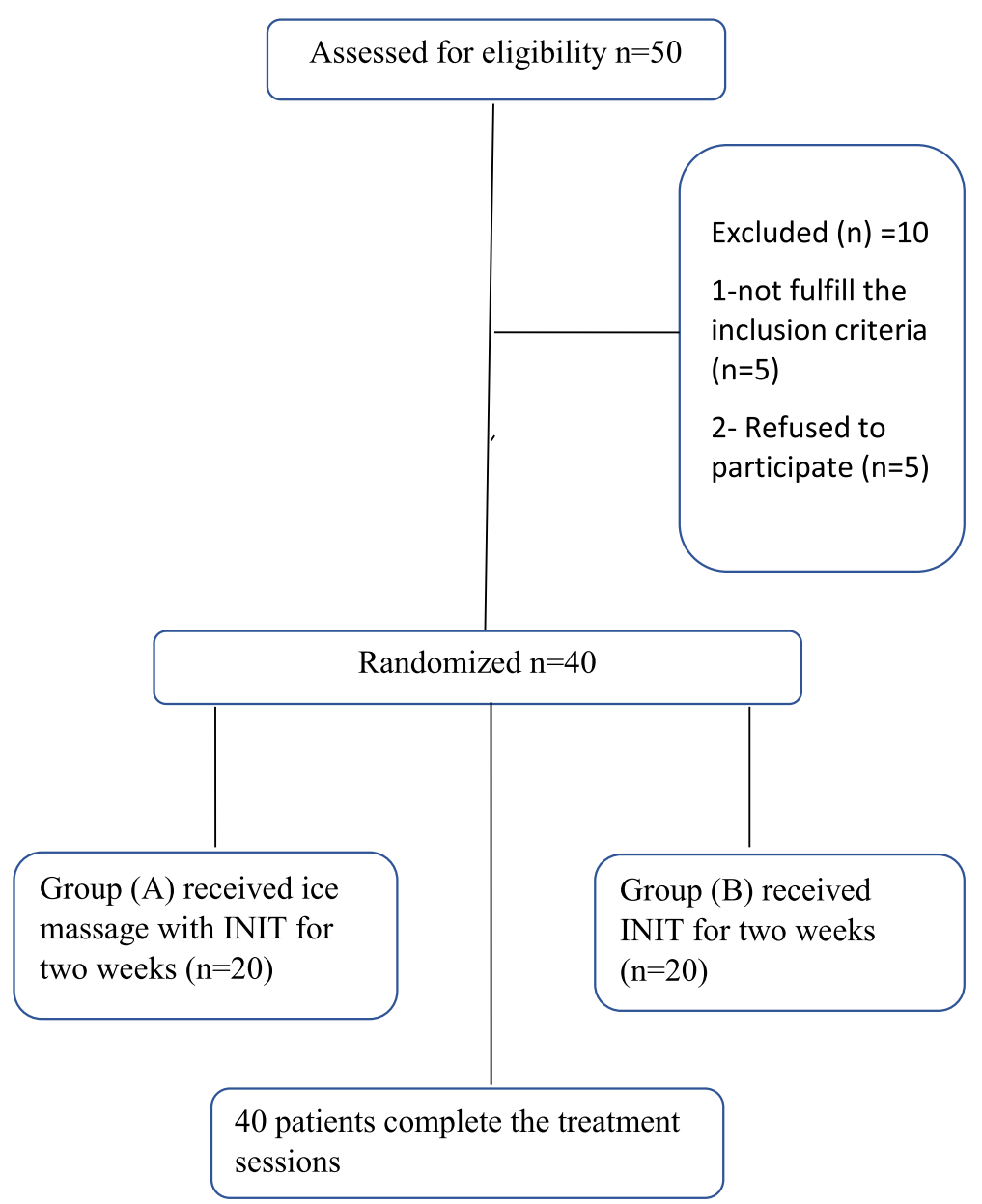

Fig. 1 Flow chart of study participants

[10]; each question had 6 options for answering, ranging from 0 (absence of disability) to 5 (full disability). The sum of all responses to questions was calculated for score ranging from 0 to 50 [11].

Pressure pain threshold assessed by valid and reliable digital electronic pressure algometer, a "force one gaugemodel FDI" (Wagner Instruments, Greenwich, CT, USA) [12]. It was used to measure active MTrP tenderness by determining the pressure pain threshold using a pressure transducer probe that was placed on the MTrp [13]. An algometer registered the force applied to a tissue by values of kilograms per square centimeter. The recorded value is the pain pressure threshold, which indicated the force amount needed for pain reproduction.

Each participant took a comfortable position, and then, the side and site of pain were identified. The upper trapezius myofascial trigger points were identified by palpation. Trigger points were palpated as tender spots on taut muscle bands, producing comparable sign coupled with jump sign. Then, a skin marker was used to mark these identified trigger points. Each participant was positioned accordingly, and a dial type pressure algometer was placed on the painful site for application of a constant vertical pressure on it. For pain expression, each participant was instructed to raise his/her hand when only slight pain was felt, until then the pressure was increased at a constant rate.

Cervical range of motion (CROM), used to measure cervical side bending to the right and left side because side bending is the isolated unilateral action of upper fiber of the trapezius [14]. The CROM device is a type of goniometer with a specific design for the cervical spine and was used for measuring CROM. Its reliability has been assessed by many studies on healthy and symptomatic subjects $[15,16]$.

The CROM device had three inclinometers one for measuring range of motion in each plane. It was placed on the participant's head while they were seated and looking directly forwards. The cervical flexion and extension were measured by a gravity dial meter, the lateral flexion was measured by another gravity dial meter, and the rotation was measured by a compass meter. The CROM accuracy was reinforced by 2 magnets positioned 
over the individual's shoulders. The CROM is superior to a single inclinometer as it does not need to be moved for measuring movement in another plane. Researchers have investigated its superiority over universal goniometer, visual estimation, and a single inclinometer [17].

\section{Treatment procedure}

For group $A$

The experimental group will receive the following:

- Cryotherapy in the form of ice massage for $10 \mathrm{~min}$ followed by a period of $5 \mathrm{~min}$ relaxation until hunting reflex and complete vasodilatation occur. Then, the therapist begins to perform the second technique [6].

- INIT approach allows the delivery of the technique in a single coordinated manner; INIT involves the following:

1. Ischemic compression (IC) was done by applying direct sustained digital pressure to the $\operatorname{TrP}$ with sufficient force ( $90 \mathrm{~s}$ or until the pain released); the maximum time is $5 \mathrm{~min}$.

2. The position of ease, strain counterstrain (SCS); a sense of "ease" was noted as the tissues reach the position in which pain vanishes from the palpated point nearly by $70 \%$.

The pressure will be maintained for $20-30 \mathrm{~s}$ and slowly return to the normal and repeat 3-5 times.

3. Muscle energy technique (MET) represented a frequently used method for attaining tonus release (inhibition) by post-isometric relaxation.

The patient will be asked to shrug the involved shoulder to the ear $7-10 \mathrm{~s}$ hold in the muscle $(20 \%$ of the available strength) with normal breathing for 5 repetitions before stretching.

\section{For group $B$}

The control group will receive the following:

- INIT will be applied as mentioned for group A.

- Both groups were treated for 6 sessions for 2 successive weeks, were given instructions about keeping their normal activities, and were advised not to perform home program as it cannot be controlled and may cause neck stress. All measurements were repeated at the end of the treatment.

\section{Sample size determination}

The planned sample size was determined depending on the assumed mean improvement of the primary outcome, the pain intensity presented by VAS. To test the null hypothesis at $\alpha$, error was set at 0.05 , with power of the study $(1-\beta)=85 \%$ and effect size $=0.87$. Power analysis was conducted using $G^{*}$ Power, and the required sample size was 42 for both groups.

\section{Statistical analysis}

- The Kolmogorov-Smirnov test was applied to the experimental and control groups and used to detect deviations from normality (Table 1). Descriptive statistics was used to compare all data which were collected from the two groups before and after treatment, the mean $(\mathrm{X})$ and standard deviation $(\mathrm{SD})$.

- Therefore, a $2 \times 2$ mixed design MANOVA was used to compare the tested variables of interest at different tested groups and measuring periods. The alpha level was set at 0.05

\section{Results}

A total of 50 patients with mechanical neck pain were eligible for inclusion, and 40 were randomized to study intervention (Fig. 1); they were assigned randomly into two equal study groups. The participant demographic data are presented in Table 1.

Statistical analysis using mixed design MANOVA revealed that there were significant within-subject effects with Wilks' lambda ( $F=3.647, p=0.003)$; partial eta squared $=0.557$ (reflecting large effect size). These results indicate that there are significant differences in pain severity, pain threshold cervical bending (right and left), and neck disability index variables within the two groups (experimental and control). As well as, there were no significant between subject effects.

There was no significant difference of treatment on pain severity ( $p=.899, F=.78)$ between means of VAS of the experimental and control groups. The experimental group showed an improvement in VAS by $54.40 \%$ and the control group by $58.27 \%$ (Table 2).

The values of the pain pressure threshold showed no statistically significant difference between the experimental and control groups $(p=.288, F=.553)$, The post-treatment measurement recorded an improvement in the pain pressure threshold of 335.37\% for the experimental group and of $238.07 \%$ for the control group (Table 2).

The post-treatment means of cervical range of motion of side bending for the right side revealed no statistically significant difference between the experimental and control groups ( $p=.094, F=.0001)$, respectively. The post-

Table 1 Demographic characteristics of patients in both groups \begin{tabular}{lllll}
\hline Group & Age (years) & Weight $(\mathrm{kg})$ & Height $(\mathrm{cm})$ & $\mathrm{BMI}\left(\mathrm{kg} / \mathrm{m}^{2}\right)$
\end{tabular}

\begin{tabular}{llllll}
\hline Control & $29.25 \pm 4.03$ & $64.70 \pm 7.68$ & $164.45 \pm 8.09$ & $23.78 \pm 1.85$
\end{tabular}

$\begin{array}{lllll}\text { Experimental } & 29.15 \pm 5.29 & 66.00 \pm 6.41 & 166.70 \pm 9.46 & 23.65 \pm 1.00\end{array}$

A significant level is set at alpha level $<0.05$ 
Table 2 Comparison between the dependent variables between study groups

\begin{tabular}{|c|c|c|c|c|c|c|c|c|c|c|}
\hline \multirow[t]{2}{*}{ Group } & \multicolumn{2}{|l|}{ VAS } & \multicolumn{2}{|c|}{ Pain threshold } & \multicolumn{2}{|c|}{ ROM SB RT } & \multicolumn{2}{|c|}{ ROM SB LT } & \multicolumn{2}{|l|}{$\mathrm{NDI}$} \\
\hline & Pre & Post & Pre & Post & Pre & Post & Pre & Post & Pre & Post \\
\hline \multicolumn{11}{|l|}{ Experimental } \\
\hline$X \pm S D$ & $\begin{array}{l}6.25 \pm \\
1.16\end{array}$ & $\begin{array}{l}2.85 \pm \\
1.18\end{array}$ & $\begin{array}{l}0.735 \pm \\
0.28\end{array}$ & $\begin{array}{l}3.20 \pm \\
0.71\end{array}$ & $\begin{array}{l}38.25 \pm \\
6.1\end{array}$ & $\begin{array}{l}44.25 \pm \\
1.831\end{array}$ & $\begin{array}{l}36.5 \pm \\
5.87\end{array}$ & $\begin{array}{l}44.75 \pm \\
1.118\end{array}$ & $\begin{array}{l}46.3 \pm \\
9.20\end{array}$ & $\begin{array}{l}19.05 \pm \\
13.05\end{array}$ \\
\hline $\mathrm{Cl}$ & $5.7-6.7$ & $2.2-3.6$ & $0.5-0.8$ & $2.6-3.2$ & $35.5-40.9$ & $43.4-45.07$ & 33.- -39.2 & $44.2-45.2$ & $40.9-51.6$ & $14.3-23.7$ \\
\hline $\begin{array}{l}\text { Percentage of } \\
\text { improvement }\end{array}$ & $54.40 \%$ & & $335.37 \%$ & & $15.69 \%$ & & $22.6 \%$ & & $58.59 \%$ & \\
\hline \multicolumn{11}{|l|}{ Control } \\
\hline$X \pm S D$ & $\begin{array}{l}6.95 \pm \\
.89\end{array}$ & $\begin{array}{l}2.90 \pm \\
1.29\end{array}$ & $\begin{array}{l}0.88 \pm \\
0.34\end{array}$ & $\begin{array}{l}2.97 \pm \\
0.59\end{array}$ & $\begin{array}{l}35.00 \pm \\
6.07\end{array}$ & $\begin{array}{l}44.15 \pm \\
1.651\end{array}$ & $\begin{array}{l}40.0 \pm \\
6.07\end{array}$ & $\begin{array}{l}44.75 \pm \\
1.118\end{array}$ & $\begin{array}{l}51.00 \pm \\
14.0\end{array}$ & $\begin{array}{l}23.70 \pm \\
6.626\end{array}$ \\
\hline $\mathrm{Cl}$ & $6.4-7.4$ & $2.3-3.4$ & $0.7-1.02$ & $2.9-3.4$ & $32.2-37.7$ & $43.4-45.07$ & $37.2-42.7$ & $44.2-45.2$ & $\begin{array}{l}45.61- \\
56.38\end{array}$ & $\begin{array}{l}19.01- \\
28.38\end{array}$ \\
\hline$F$ & 0.86 & 0.78 & 0.35 & 0.55 & 0.09 & 0.0001 & 0.022 & 0.0001 & 4.73 & 7.03 \\
\hline Sig. & .059 & .899 & .153 & .288 & .094 & 1 & .072 & 1 & .219 & .164 \\
\hline $\begin{array}{l}\text { Percentage of } \\
\text { improvement }\end{array}$ & $58.27 \%$ & & $238.07 \%$ & & $26.43 \%$ & & $11.88 \%$ & & $53.53 \%$ & \\
\hline
\end{tabular}

$X$ mean, $S D$ standard deviation, Sig. significant, $\mathrm{Cl}$ confidence interval

treatment measurement showed an improvement in the cervical side bending by $15.69 \%$ for the experimental group and $26.43 \%$ for the control group (Table 2 ).

There was no statistically significant difference posttreatment between two groups, as the mean for the experimental group was $44.75 \pm 1.118$ and for the control group was $44.75 \pm 1.118$ with $p=.072$ and $F=.0001$. The post-treatment measurement showed an improvement in the cervical side bending (left side) by $22.60 \%$ for the experimental group and $11.88 \%$ for the control group (Table 2).

The results indicated that there was no statistically significant difference between the experimental and control groups $(p=.164, F=7.035)$. The post-treatment measurement reported an improvement in NDI by $58.59 \%$ for the experimental group and $53.53 \%$ for the control group (Table 2).

\section{Discussion}

Research regarding ice application on non-specific neck pain is still debatable in the scientific literature since the application has a lot of argument and contraindication international attention with the last 10 years. There is an ongoing need for further powered high-quality RCTs on the effect of cold and heat therapy on acute musculoskeletal injury [8].

So the purpose of this study was directed to compare the effect of adding ice massage to INIT versus the effect of INIT alone on pain intensity, PPT, NDI, and CROM during treatment of upper trapezius active trigger points in subjects with mechanical neck pain. Using ice massage is the best method after the cold gel packs to decrease skin temperature by using ice for prolonged time without causing ice complications such as frost bite and to reach the desired vasodilatation caused by the hunting response of applied ice massage [7].

\section{Regarding the effects of ice massage with integrated neuromuscular inhibition technique on active trigger} points in subjects with mechanical neck pain

It was hypothesized that there will be no significant effect between the groups in improving the measured outcomes. According to the results of the study, we accept the null hypothesis. There was no significant effect between the two groups. But, on the opposite side, there were improvements in the outcomes in favor to the experimental group in the following outcomes compared to the control: PPT (335.37 to $238.07 \%$ ), right side bending (22.6 to $11.88 \%)$, and NDI (22.6 to $11.88 \%$ ).

The improvement in the pain threshold in adding the ice massage to the INIT supported our findings and may be explained by Algafly et al. [18], who directed his study to determine the impact of the application of cryotherapy on nerve conduction velocity (NCV), pain threshold $(\mathrm{PTH})$, and pain tolerance (PTO). The results suggested that cryotherapy can increase PTH and PTO at the ankle and this was associated with a significant decrease in NCV. Reduced NCV at the ankle may be a mechanism by which cryotherapy achieves its clinical goals. The short-term use of cryotherapy not only acts on decreasing pain, but also enhances the function and quality of life in patients with knee osteoarthritis as stated by Dantas et al. [19].

Our results were different from Kaprail et al. [14], who investigated whether physical therapy techniques to inactivate myofascial trigger points can reduce symptoms and improve shoulder and neck function in daily 
activities in the population of chronic periarthris shoulder patients. Treatment starting with inactivation of the active myofascial trigger points by manual techniques employing compression technique combined with the intermittent cold application by using ice cubes followed by myofascial release, friction massage, and stretching the muscle daily for 2 weeks with follow-up on the 14th day was given. There was an increase in neck flexion and neck extension and a decrease in neck disability index (NDI) and pain on visual analogue scale (VAS).

The results of Kaprail et al. [14] may be different from the current study due to the difference in application that they applied the ice (for $20 \mathrm{~min}$ ) through the treatment not before the treatment that may lead to prolonged cooling effect resulting in slowing of peripheral nerve conduction due to reduction in skin afferents, resulting in deceasing pain intensity and allowing the myofascial release to increase neck range of motion and improve function. This may be the cause of not achieving significant difference between the two groups in the present study that the ice massage is applied $10 \mathrm{~min}$ followed by a period of $5 \mathrm{~min}$ relaxation and then the INIT technique, so temperature may be reduced than the effective level that can produce effect on the surrounding tissues in a significant value. Besides that, this paper applied the study on 10 patients only and its design was repeated measures on the same group while ours fulfilled the required sample size number according to the power analysis.

Supporting our results, Howatson et al. [6] stated that ice massage is ineffective in reducing the indirect markers associated with exercise-induced muscle damage.

Finally, Bleakley et al. [5] performed a systematic review to assess the evidence of cryotherapy in the treatment of acute soft tissue injuries. There was marginal evidence that ice plus exercise is most effective, after ankle sprain and post-surgery. There was little evidence that the addition of ice to compression had any significant effect.

\section{Regarding the effects of INIT on active trigger points in subjects with MNP}

Concerning the results in the current study, there was a non-significant difference between the two groups, but the results of the experimental group revealed that there was a significant improvement after treatment in the values of VAS (58.27\%), PPT (238.07\%), NDI (53.53\%), and ROM (side bending $\mathrm{R}$ 26.43\%, side bending $\mathrm{L}$ 11.88).

The INIT effect might be related to the combined effect of three manual treatment techniques. First of all, intermittent ischemic compression induced pain reduction through stimulating A-beta fibers which influence pain gate during pressure, as well as increasing circulation while the pressure release [20-24]. Secondly, strain counterstrain allowed pain reduction, functional and ROM enhancement, and muscle amplitude improvement via placing the muscle at the passive shortened position. Such position improved the circulation to the muscle and helped restoration of muscle spindle normal activity [2527]. Thirdly, muscle energy technique promoted pain relief, as well as functional and ROM improvement through working on autogenic muscle inhibition. Such technique was performed via application of isometric muscular contraction that activates the Golgi tendon organ, resulting in muscle relaxation. Additionally, muscle energy technique increased ROM through changing muscle extensibilityreflex relaxation, viscoelasticity, and stretching $[24,26]$.

The results of this study agreed with a previous study that demonstrated the INIT effectiveness in improving pain, ROM, and NDI for treating upper trapezius trigger points [21]. Moreover, Nagrale et al. [28] proved that INIT was an effective method for TrP treatment through producing pain relief, stiffness reduction, and functional improvement.

In the same line, Jyothirmai et al. [29] has evaluated the impact of INIT technique on people having upper trapezius trigger points. One group received INIT plus the strength program, while the other group received only INIT. Measured variables included VAS, CROM, and NDI. The results of that study showed refinement in the two groups [29, 30].

Finally, Abd El-Azeim et al. [31] investigated the effect of INIT and kinesiotape (KT) on upper trapezius myofascial trigger points. They found that the INIT was superior and most effective in the management of active trigger points at the upper trapezius muscle than kinesiotape [31].

The study was limited by the psycho-physiological factor which may have interfered with the patient's performance and response, no matching between male and female; there was no availability for blinding for both patients and therapist, due to ice application that cannot be masked.

\section{Conclusion}

The short-term treatment of adding ice massage to INIT is an effective method to reduce pain, improve pain threshold and function, and increase side bending of cervical region in subjects with mechanical neck pain and active trigger points at the upper trapezius muscle without statistically significant difference from INIT.

\footnotetext{
Abbreviations

MTrP: Myofascial trigger point; INIT: Integrated neuromuscular inhibition technique; BMI: Body mass index; VAS: Visual analogue scale; PPT: Pain pressure threshold; NDI: Arabic version of neck disability index; CROM: Cervical range of motion
} 


\section{Acknowledgements}

I would like to express my gratitude and appreciation to the participants who agreed to go forth with our study, without them the study would not have come to be. All our best wishes to those valuable and supporter of this study.

\section{Authors' contributions}

$\mathrm{DM}$ and $\mathrm{AH}$ both contributed to the writing and reviewing of the manuscript. All authors read and approved the manuscript.

\section{Funding}

There were no funding sources from any organizations.

\section{Availability of data and materials}

The data supporting the findings of this study are available on request from the corresponding author $(\mathrm{H} \mathrm{M})$. The data are not publicly available due to containing information that could compromise research participant privacy.

\section{Ethics approval and consent to participate}

The study protocol was approved by the research ethical committee of Faculty of Physical Therapy (NO: P. T. REC/012/001943) and registered at Pan African Clinical Trial Registry. The unique identification number for the registry is PACTR20180840946173.

All subjects received verbal and written explanation for the purpose of the study, and if they agreed to participate, they signed the consent form which was approved by the Faculty of Physical Therapy.

\section{Consent for publication}

The participants whose images were enrolled in the study signed a consent for publication form which was approved by the Faculty of Physical Therapy.

\section{Competing interests}

The authors declare that they have no competing interests.

\section{Author details}

${ }^{1}$ Cairo University, Giza, Egypt. ${ }^{2}$ Basic Science Department, Faculty of Physical Therapy, Cairo University, Giza, Egypt.

\section{Received: 11 May 2020 Accepted: 29 July 2020}

\section{Published online: 04 November 2020}

\section{References}

1. Kang B, Kim T. Relief of chronic neck pain depending on the type of forest therapy: comparison of the therapeutic effects of forest bathing alone versus forest bathing with exercise. Ann Rehabil Med. 2015;39(6):957-63.

2. Holy DG, Protani M. The epidemiology of neck pain. Best Pract Res Clin Rheumatol. 2010;24(6):783-92.

3. Murray CJL, Lopez AD. Measuring the global burden of disease. Engl I Med. 2013;369(5):448-57.

4. Lluch E, Nijs J, De Koonjng M. Prevalence, incidence, location, and pathophysiology of myofascial trigger points in patients with spinal pain: a systemic literature review. J Manip Physiol Ther. 2015;38(8):587-600.

5. Bleakly, McDonough, MacAuley. The use of ice in the treatment of acute soft tissue injury: a systematic review of randomized controlled trials. Am . Sports Med. 2004;32(1):251-61.

6. Howatson G, Gaze D, Van Someren KA. The efficacy of ice massage in the treatment of exercise-induced muscle damage. Scand I Med Sci Sports. 2005;15(6):416-22.

7. William JR, Srikantaiah S, Mani R. Cryotherapy for acute non-specific neck pain. Cochrane Database Syst Rev. 2013;8.

8. Malanga GA, Yan N, Stark J. Mechanisms and efficacy of heat and cold therapies for musculoskeletal injury. Postgrad Med. 2015;127(1):57-65.

9. Boonstra AM, Schiphorst Preuper HR, Reneman MF. Reliability and validity of visual analogue scale for disability in patients with chronic musculoskeletal pain. Int J Rehabil Res. 2008;31(2):165-9.

10. Vernon $\mathrm{H}$, Schneider M. Chiropractic management of myofascial trigger points and myofascial pain syndrome: a systematic review of the literature. J Manip Physiol Ther. 2009;32(1):14-24.

11. MacDermid JC, Walton DM, Avery S, Blanchard A, Etruw E, McAlpine C, Goldsmith CH. "Measurement properties of the neck disability index": a systematic review. J Orthop Sports Phys Ther. 2009;39(5):400-17.
12. Fabio A. Pressure algometry in healthy subjects: inter-examiner variability. Scand J Rehabil Med. 1998:30(1):3-8.

13. Ethne L, Laurie D. Reliability of clinical pressure-pain algometric measurements obtained on consecutive days. Phys Ther. 1998;78(2):1609.

14. Kaprail M, Jetly S, Sarin A, Kaur P. To study the effect of myofascial trigger point release in upper trapezius muscle causing neck disability in patients with chronic periarthritis shoulder. 2019;5(1):1-4.

15. Jordan K. Assessment of published reliability studies for cervical spine range-ofmotion measurement tools. J Manip Physiol Ther. 2000;23(3):180-95.

16. Tousignant $M, L d B, O$ Donoughue $S$, Grahovac $S$. Criterion validity of the cervical range of motion (CROM) goniometer for cervical flexion and extension. Spine. 2000;25(3):324-30

17. Tousignant M, Smeesters C, Breton AM, Breton E, Corriveau H. Criterion validity study of the cervical range of motion (CROM) device for rotational range of motion on healthy adults. J Orthop Sports Phys Ther. 2006;36(4):242-8.

18. Dantas LO, Breda CC, Serrao PMS, Jorge AS, Salvini TF. Cryotherapy short-term use relieves pain, improves function and quality of life in individuals with knee osteoarthritis-randomized controlled trial. Osteoarthr Cartil. 2017;25:S174.

19. Algafly AA, George KP. The effect of cryotherapy on nerve conduction velocity, pain threshold and pain tolerance. Br J Sports Med. 2007;41(6):365-9.

20. Gemmel $\mathrm{H}$, Miller $\mathrm{P}$, Nordstrom $\mathrm{H}$. Immediate effect of ischaemic compression and trigger point pressure release on neck pain and upper trapezius trigger point: a randomized controlled trial. Clin Chiropr. 2008;11(1):30-6.

21. Sibby, George M, Narasimman, Kavitha V, Effectiveness of integrated neuromuscular inhibitory technique and LASER with stretching in the treatment of upper trapezius trigger points (2010).

22. Amir I. Efficacy of ischaemic compression technique in combination with strain counterstrain technique in managing upper trapezius myofascial trigger point pain. Indian J Physiother Occup Ther. 2010;4(2):10-5.

23. Jyotsna M, Reddy V, Madhavi K. Effectiveness of integrated neuromuscular inhibitory technique (INIT) on pain, range of motion ad functional abilities in subjects with mechanical neck pain. Int J Pharm Res Bio Sci. 2013;2(6):584-93.

24. Nambi GS, Sharma R, Inbasekaran D, Vaghesiya A, Bhatt U. Difference in effect between ischemic compression and muscle energy technique on upper trabezius myofascial trigger points: comparative study. Int J Health Allied Sci. 2013;2(1):17.

25. Meseguer AA, Fernández-de-las-Peñas C, Navarro-Poza JL, Rodríquez-Blanco C, Boscá Gandia JJ. Immediate effects of the strain/counterstrain technique in local pain evoked by tender points in the upper trapezius muscle. Clin Chiropractic. 2006;9(3):112-8.

26. Lewis C, Souvlis T, Sterling M. Strain counterstrain therapy combined with exercise is not more effective than exercise alone on pain and disability in people with acute low back pain: a randomized trial. J Phys. 2011;57(2):91-8.

27. Kumar GY, Sneha P, Sivajyothi N. Effectiveness of muscle energy technique, ischemic compression and strain counterstrainon upper trabezius trrigger points: a comparative study. Int J Educ Sports Health. 2015;1(3):22-6.

28. Nagrale AV, Glynn P, Joshi A, Ramteke G. The efficacy of an integrated neuromuscular inhibition technique on upper trapezius trigger points in subjects with non-specific neck pain: a randomized controlled trial. J Manual Manipulative Ther. 2010;18(1):37-43.

29. Jyothirmai B, Senthil Kumar K, Raghavkrishna S, Madhavi K. Effectiveness Of integrated neuromuscular inhibitory technique (INIT) with specific strength training exercises in subjects with upper trapezius trigger points. Int I Theor Phys. 2015;2(5):759-64.

30. Saadat Z, Hemmati L, Pirouzi S, Ataollahi M, Ali-mohammadi F. Effects of integrated neuromuscular inhibition technique on pain threshold and pain intensity in patients with upper trapezius trigger points. J Bodyw Mov Ther. 2018;22(4):937-40

31. Abd El-Azeim AS, Ahmed SEB, Draz AH, Elhafez HM, Kattabei OM. Integrated neuromuscular inhibition technique versus kinesiotape on upper trapezius myofascial trigger points a randomized clinical trial. international journal of physiotherapy, 5(3), 105-112.Bleakly, McDonough and MacAuley. The use of ice in the treatment of acute soft tissue injury: a systematic review of randomized controlled trials. Am J Sports Med. 2018;32(1):251-61.

\section{Publisher's Note}

Springer Nature remains neutral with regard to jurisdictional claims in published maps and institutional affiliations. 